\title{
DAMPAK APLIKASI INSEKTISIDA PERMETRIN TERHADAP HAMA PENGISAP BUAH HELOPELTIS SPP. (HEMIPTERA: MIRIDAE) DAN ARTROPODA NON-TARGET PADA PERTANAMAN KAKAO $($ (THEOBROMA CACAO L.)
}

\author{
Rosma Hasibuan ${ }^{1}$, I Gede Swibawa ${ }^{1}$, Lestari Wibowo ${ }^{1}$, Sudi Pramono ${ }^{1}$, dan Agus M. Hariri ${ }^{1}$
}

\begin{abstract}
Impact of Permethrin-Insecticide Application on Mirid Pest of Cocoa Helopeltis spp. (Hemiptera: Miridae) and on Non-target Arthropods in Cocoa Plantations (Theobroma cacao L.). Cocoa mirid bugs, Helopeltis spp., (Hemiptera: Miridae) are the most important pest of cocoa in Indonesia. A field study was conducted to investigate the effect of permethrin on cocoa mirids and non-target arthropods at a cocoa plantation in specific place. A randomized complete block design was used in which each of four blocks consisted of 5 treatments ( 4 concentrations of permethrin; 50; 100; 200 ; and $250 \mathrm{ppm}$ and control). The results indicated that the application of permethrin significantly increased the coosa mirids mortality throughout all sprayed cocoa trees (up to $100 \% 72 \mathrm{~h}$ after application). Even at $1 \mathrm{~h}$ after application, the percentage of cocoa mirids mortality $(29.2 \%-53.9 \%)$ on cocoa trees sprayed with permethrin at concentrations of $50-$ $250 \mathrm{ppm}$ was significantly higher than that on control plant $(3.6 \%)$. At $72 \mathrm{~h}$ after treatments, application of permethrin at concentrations of 200 and $250 \mathrm{ppm}$ caused a complete kill (mortalty of $100 \%$ ) in the test mirids. Meanwhile, ground cloths caught at least 22 families of above-ground arthropods that were found killed by permethrin applications. Moreover, the number of non-target arthropods killed by permethrin at concentrations of $100-250 \mathrm{ppm}(27.3-85.3$ individuals/ground cloth) were significantly higher than that on control trees. These results demonstrated that despite high efficacy of permethrin in controlling of cocoa mirids (Helopeltis spp.), its application also had adverse effects on non-target arthropods in cocoa plantations.
\end{abstract}

Key words: cocoa mirids, Helopeltis spp., cocoa tree, permethrin, insecticide

\section{PENDAHULUAN}

Tanaman kakao (Theobroma cacao L.) yang diduga berasal dari daerah sekitar sungai Amazon telah dibudidayakan secara luas di beberapa negara terutama di Malaysia dan Indonesia. Permintaan yang tinggi akan biji kakao dari luar negeri mengakibatkan tanaman kakao menjadi komoditas primadona ekspor non-migas sebagai penghasil devisa di Indonesia. Oleh karena itu, tanaman kakao telah dibudidayakan secara intensif (Siregar et al., 1999). Khusus di Provinsi Lampung, perkebunan tanaman kakao terus berkembang dan tidak hanya merupakan monopoli perkebunan besar milik negara tetapi juga perkebunan swasta.

Namun dalam upaya peningkatan produktivitas, budidaya tanaman kakao seringkali mengalami kendala, terutama dengan adanya serangan hama dan penyakit. Pengisap buah kakao Helopeltis spp. (Hemiptera: Miridac) merupakan salah satu hama penting pada tanaman kakao karena secara langsung dapat menurunkan produksi kakao
(Kalshoven, 1981; Sudarmadji et al, 1990). Serangan hama Helopeltis spp. telah tersebar luas dan mencakup wilayah Srilangka, Papua New Guinea, Indonesia, Malaysia, Afirika Barat, dan Afrika Timur (Smith, 1978). Dari 13 spesies Helopeltis spp. yang menyerang tanaman kakao, dua spesies terdapat di pulau Jawa yaitu Helopeltis antonit Sign. dan Helopeltis theivora Watt sedangkan di Malaysia adalah Helopeltis theobroma dan Papua New Guinea Helopeltis clafiver (Alias et al., 1988). Hama Helopeltis spp. (nimfa dan imago) menyerang tanaman kakao dengan cara mengisap buah yang masih muda dan mengakibatkan luka hitam yang dikenal dengan gejala nekrotik buah (Alias et al., 1988; Muhamad \& Way, 1995).

Teknik pengendalian yang umum dilakukan untuk mengendalikan hama Helopeltis spp. adalah dengan penyemprotan insektisida, salah satunya adalah insektisida permetrin (golongan piretroid sintetik) (Chung \& Wood, 1989). Tingginya penggunaan insektisida permetrin disebabkan oleh sifat kimianya yang mirip dengan insektisida nabati 
yang dianggap lebih ramah terhadap lingkungan. Penelitian tentang uji efikasi insektisida permetrin terhadap beberapa jenis hama yang menyerang tanaman kakao telah banyak dilakukan, namun informasi tentang dampak burak insektisida ini terhadap lingkungan dan organisme non-target masih kurang memadai. Penelitian ini bertujuan untuk menyelidiki dampak aplikasi insektisida permetrin terhadap hama pengisap buah kakao Helopeltis spp. dan artropoda non-target pada tanaman kakao.

\section{METODE PENELITIAN}

Percobaan dilaksanakan di perkebunan kakao swasta milik PT Pluit Makmur Lestari, Cabang Lampung Desa Bernung, Kecamatan Gedung Tataan, Lampung Selatan. Luas perkebunan kakao yang dimiliki oleh perusahaan ini adalah 63,7 ha. yang dibagi menjadi dua wilayah yaitu Afdeling I dan Afdeling II. Lokasi percobaan dipilih pada areal tanaman kakao yang telah berproduksi (berbuah) dengan luas kurang lebih 1,0 ha. Percobaan dilakukan mulai dari bulan Januari hingga bulan April 2002.

Sebelum percobaan dimulai, survei lokasi ke beberapa perkebunan kakao di Provinsi Lampung telah dilakukan. Dari setiap lokasi survei, sejumlah hama pengisap buah kakao (Helopeltis spp.) telah dikumpulkan. Langkah selanjutnya adalah memelihara hama Helopeltis spp. dan mengembangbiakkannya di dalam kurungan kasa nylon berbentuk kubus $(40 \times 40 \times 50 \mathrm{~cm})$ di rumah kaca. Pada awalnya, perkembangan koloni hama pengisap buah kakao di rumah kaca mengalami masalah karena tingkat kematian Helopeltis spp. sangat tinggi (dimangsa oleh semut) dan tingkat reproduksi yang rendah. Namun dengan memperbaiki struktur kurungan dan cara pemberian pakan (buah kakao) secara tepat masalah tersebut dapat diatasi.

Percobaan dilaksanakan pada tanaman kakao varitas Upper dari klon Malaysia Barat yang sudah berbuah. Satuan percobaan yang digunakan adalah satu pohon kakao dengan jarak antarpetak adalah dua baris pohon kakao. Sedangkan jarak antarkelompok (ulangan) adalah empat baris pohon kakao. Setiap kelompok ditandai dengan tiang/papan label. Selanjutnya setiap pohon percobaan diberi tanda (dicat dengan fylox berwarna merah) dan label seng berbentuk empat persegi $(10 \times 15 \mathrm{~cm})$ yang digantungkan dekat buah yang telah ditentukan.
Perlakuan dalam percobaan disusun dalam Rancangan Acak Kelompok (RAK) yang terdiri atas lima perlakuan konsentrasi permetrin $(50 ; 100 ; 200$; $250 \mathrm{ppm}$ = nama dagang Protect $100 \mathrm{EC}$ ) dan satu kontrol (tanpa aplikasi insektisida). Setiap perlakuan diulang sebanyak 4 kali (ulangan sebagai kelompok). Pengelompokkan dilakukan berdasarkan arah pergerakan matahari sehingga seluruh perlakuan pada setiap kelompok mendapatkan cahaya/sinar matahari yang sama.

Sebelum insektisida diaplikasikan, kain hampar (ground cloth) berwama putih berukuran $1 \mathrm{~m}$ x I m telah dibentangkan di bawah pohon terok dengan cara mengikatkan ke empat tali kain hampar (yang terdapat pada setiap sudut kain) ke pohon kakao di sekitarnya. Penggunaan kain hampar dimaksudkan untuk dapat menduga kepadatan populasi artropoda non-target yang mati terkena insektisida permetrin.

Aplikasi insektisida (sesuai dengan jenis perlakuan) dilakukan dengan menggunakan alat semprot punggung (knapsack sprayer) berkapasitas 10 liter. Setiap pohon kakao yang telah ditentukan disemprot dengan mengarahkan nozzle ke cabang dan batang dengan arah gerakan berbentuk huruf $\mathrm{T}$. Banyaknya larutan (volume semprot) yang digunakan adalah 500 1/ha atau $500 \mathrm{ml} /$ pohon. Penyemprotan dilakukan secara merata dan membasahi buah yang akan disungkup. Setelah insektisida kering (kurang lebih 10 menit), buah kakao yang telah ditandai dibungkus dengan kurungan kasa nylon berbentuk silinder dan ke dalam kurungan tersebut dimasukkan sebanyak 20 ekor Helopeltis spp. imago.

Pengamatan dilakukan dengan cara menghitung jumlah serangga uji (hama Helopeltis spp.) yang mati pada kurungan silinder pada 1, 2, 4, 24, 48, dan 72 jam setelah aplikasi (jsa). Khusus artropoda non-target, pengamatan dilakukan hanya satu kali yaitu 24 jsa dengan cara memeriksa kain hampar dan menghitung jumlah artropoda yang terbunuh. Untuk menentukan jenis artropoda nontarget yang terbunuh karena aplikasi permetrin, maka semua artropoda tersebut dikumpulkan dan dimasukkan ke dalam botol koleksi yang berisi alkohol $70 \%$ untuk diawetkan. Kemudian spesimen artropoda non-target tersebut dipisahkan menurut ciri dan bentuk morfologinya dan diletakkan pada botol koleksi yang berbeda. Spesimen tersebut kemudian di identifikasi di Laboratorium Artropoda Hama Fakultas Pertanian. Jumlah hama kakao yang terbunuh diamati pada setiap jam pengamatan, 
kemudian persentase kematian $\left(P_{5}\right)$ dihitung sebagai berikut:

$$
\mathrm{P}_{\mathrm{s}}=\left(\mathrm{N}_{\mathrm{l}} / \mathrm{N}_{0}\right) \times 100
$$

Keterangan: $P_{s}=$ persentase kematian; $N_{1}$ - jumlah serangga uji yang mati setelah perlakuan; dan $\mathrm{N}_{0}=$ jumlah total serangga uji sebelum perlakuan ( 20 ckor).

Kemudian persentase kematian serangga uji dan jumlah artropoda non-targhet yang terbunuh dianalisis dengan sidik ragam, dilanjutkan dengan uji perbandingan nilai tengah (Duncan's Multiple Range Test, = Duncan's MRT dengan taraf nyata $\alpha=0,05$ ) dengan menggunakan perangkat pengolah data SAS (SAS Institute Inc., 1988).

\section{HASIL DAN PEMBAHASAN}

\section{Efikasi insektisida permetrin terhadap hama Helopeltis spp.}

Hasil percobaan lapang menunjukkan bahwa perlakuan insektisida permetrin pada pertanaman kakao secara konsisten berpengaruh nyata terhadap mortalitas hama pengisap buah kakao, Helopeltis spp.. pada setiap jam pengamatan (Nilai Uji F berkisar antara 8,67 hingga 431,92 ; Nilai $\mathrm{Pr}>\mathrm{F}$ berkisar antara 0,0001 hingga 0,0002 ; Tabel 1). Hal ini menunjukkan bahwa semua konsentrasi insektisida permetrin yang diaplikasikan dengan eara penyemprotan pada tanaman kakao dapat menurunkan populasi hama
Helopeltis spp. secara nyata dibandingkan dengan kontrol (tanpa aplikasi insektisida).

Secara rinci, hasil pengamatan pada 1 jsa telah menunjukkan adanya kematian serangga uji (Helopeltis spp.) pada semua perlakuan insektisida permetrin (konsentrasi $50-250 \mathrm{ppm}$ ) yang berkisar antara $29,2 \%$ hingga $53,9 \%$ dan kematian hama kakao ini nyata lebih tinggi dibandingkan dengan kematian pada kontrol sebesar $3,6 \%$ (Nilai $F=8,67$ dan $\operatorname{Pr}>F=0,0002$; Tabel 1). Hasil yang sama juga terjadi pada setiap pengamata selanjutnya, yaitu 2 jsa -72 jsa yang menunjukkan persentase kematian yang nyata lebih tinggi dibandingkan dengan kematian pada kontrol (Tabel 1). Dengan demikian, persentase kemataan hama pengisap buah kakao pada perlakuan konsentrasi terendahpun (50 ppm) nyata lebih tinggi dibandingkan dengan kontrol (Tabel 1).

Hasil percobaan di akhir pengamatan ( $72 \mathrm{jsa})$ menunjukkan bahwa dua perlakuan insektisida permetrin (konsentrasi 200 dan $250 \mathrm{ppm}$ ) telah membunuh semua hama Helopeltis spp. yang diuji (kematian 100\%; Tabel 1). Sedangkan besarnya kematian pada konsentrasi 50 ppm dan $100 \mathrm{ppm}$ adalah $97,5 \%$ dan $98,8 \%$ dan persentase kematian ini nyata lebih tinggi dibandingkan kematian serangga uji pada tanaman kontrol (Nilai $\mathrm{F}=431,92$ dan $\operatorname{Pr}>\mathrm{F}=$ 0,0001: Tabel 1). Hal ini menunjukkan bahwa insektisida permetrin dalam kondisi lapang dapat efektif membunuh hama pengisap buah kakao.

Tabel 1. Rata-rata persentase kematian pengisap buah (Helopeltis spp.) pada tanaman kakao yang telah disemprot dengan beberapa konsentrasi insektisida permetrin

\begin{tabular}{lcccccc}
\hline \multirow{2}{*}{ Perlakuan } & \multicolumn{6}{c}{ Persentase kematian pada } \\
\cline { 2 - 7 } & 1 jsa & 2 jsa & 4 jsa & 24 jsa & 48 jsa & 72 jsa \\
\hline Kontrol & $3,6 \mathrm{~d}$ & $3,6 \mathrm{c}$ & $11,0 \mathrm{c}$ & $11,0 \mathrm{~d}$ & $11,0 \mathrm{c}$ & $11,0 \mathrm{~b}$ \\
$50 \mathrm{ppm}$ & $29,2 \mathrm{c}$ & $50,5 \mathrm{~b}$ & $65,1 \mathrm{~b}$ & $89,9 \mathrm{c}$ & $93,8 \mathrm{~b}$ & $97,5 \mathrm{a}$ \\
$100 \mathrm{ppm}$ & $45,0 \mathrm{abc}$ & $63,2 \mathrm{ab}$ & $86,3 \mathrm{a}$ & $93,8 \mathrm{bc}$ & $96,3 \mathrm{ab}$ & $98,8 \mathrm{a}$ \\
$200 \mathrm{ppm}$ & $49,2 \mathrm{ab}$ & $71,3 \mathrm{a}$ & $98,8 \mathrm{a}$ & $98,8 \mathrm{ab}$ & $100,0 \mathrm{a}$ & $100,0 \mathrm{a}$ \\
$250 \mathrm{ppm}$ & $53,9 \mathrm{a}$ & $73,2 \mathrm{a}$ & $98,8 \mathrm{a}$ & $100,0 \mathrm{a}$ & $100,0 \mathrm{a}$ & $100,0 \mathrm{a}$ \\
\hline Nilai F & $8,67^{* *}$ & $11,07^{* *}$ & $32,61^{*+}$ & $241,09^{* *}$ & $333,73^{\circ *}$ & $431,92^{\circ}$ \\
Pr $>\mathrm{F}$ & 0,0002 & 0,0001 & 0,0001 & 0,0001 & 0,0001 & 0,0001 \\
Duncan's MRT & 15,21 & 18,76 & 14,51 & 5,41 & 4,65 & 4,12 \\
\hline
\end{tabular}

Keterangan: jsa = jam setelah aplikasi; ${ }^{10}$ Nilai tengah pada satu kolom yang diikuti oleh huruf yang sama tidak berbeda nyata berdasarkan Duncan's Multiple Range Test dengan taraf nyata $\alpha=0,05$;

* pengaruh perlakuan berbeda sangat nyata 
Tabel 2. Daftar jenis artropoda non-target yang terbunuh akibat penyemprotan insektisida permetrin pada pertanaman kakao yang tertangkap kain hampar (ground cloth)

\begin{tabular}{llll}
\hline No & Famili artropoda non-target & No & Famili artropoda non-target \\
\hline 1 & Formicidae & 12 & Culicidae \\
2 & Blattidae & 13 & Braconidae \\
3 & Acrididac & 14 & Tetragnathidae \\
4 & Salticidae & 15 & Chrysomelidae \\
5 & Nitidulidae & 16 & Coccinellidac \\
6 & Curculionidae & 17 & Dryinidae \\
7 & Carabidae & 18 & Hispidae \\
8 & Cryptomhynchinac & 19 & Thorisidae \\
9 & Drosophilidae & 20 & Lepidoptera (larva)* \\
10 & Elateridac & 21 & Oxyopidae \\
11 & Staphylinidae & 22 & Lycosidae \\
\hline
\end{tabular}

Keterangan: Famili No. I s.d. 20 adalah serangga (90,91\%) sedangkan No. 21 dan 22 adalah laba-laba $(9,09 \%) ;$ * Larva yang tertangkap tidak diketahui nama familinya tetapi dipastikan dari Ordo Lepidoptera

Dampak Aplikasi Permetrin terhadap Artropoda Nontarget

Hasil pemeriksaan pada kain hampar (ground cloth) yang dibentangkan di bawah pohon kakao dan hasil identifikasi di laboratorium menunjukkan adanya 22 famili artropoda non-target yang terbunuh akibat penyemprotan insektisida permetrin yang terdiri atas kelas serangga dan laba-laba (Tabel 2). Di antara jenis yang terbunuh di atas, kelas yang lebih banyak terbunuh adalah serangga $(90,9 \%$; Tabel 2$)$. Menurut Bigger (1993) dan Khoo \& Mohamad (1986), dalam agroekosistem kakao diduga banyak artropoda nontarget yang bermanfaat secara langsung maupun tidak langsung dalam menjaga kestabilan agroekosistem tanaman kakao. Banyaknya jenis artropoda yang terbumuh pada kain hampar menunjukkan bahwa aplikasi insektisida permetrin pada pertanaman kakao di lapang dapat membahayakan keberadaan organisme lain (terutama artropoda).

Jumlah artropoda non-target yang terbunuh akibat perlakuan insektisida permetrin $(27,3 ; 47,0$; dan 85,3 ekor/kain hampar pada konsentrasi 100; 200; dan $250 \mathrm{ppm}$ ) nyata lebih tinggi dibandingkan dengan kontrol (4,333 ekor/kain hampar) kecuali konsentrasi terendah ( $50 \mathrm{ppm}=16,7$ ekor/kain hampar). Selanjutnya, pada konsentrasi tertinggi (250 ppm). insektisida permetrin membunuh artropoda non- target sebanyak 85,3 ekor/kain hampar dan jumlah ini nyata lebih besar dibandingkan dengan perlakuan permetrin lain termasuk kontrol (Nilai $\mathrm{F}=25,13$; $\mathrm{Pr}>$ $\mathrm{F}=0,0001$ : Tabel 2).

Tabel 3. Jumlah artropoda non-target yang terbunuh akibat penyemprotan insektisida permetrin pada pertanaman kakao

\begin{tabular}{ll}
\hline $\begin{array}{l}\text { Periakuan } \\
\text { (konsentrasi permetrin) }\end{array}$ & $\begin{array}{l}\text { Jumlah artropoda } \\
\text { Non-target yg terbunuht } \\
\text { (ekor/kain hampar) }\end{array}$ \\
\hline Kontrol & $4,3 \mathrm{~d}^{2}$ \\
$50 \mathrm{ppm}$ & $16,7 \mathrm{~cd}$ \\
$100 \mathrm{ppm}$ & $27,3 \mathrm{be}$ \\
$200 \mathrm{ppm}$ & $47,0 \mathrm{~b}$ \\
$250 \mathrm{ppm}$ & $85,3 \mathrm{a}$ \\
\hline Nilai F & $25,13^{* *}$ \\
Pr $>\mathrm{F}$ & 0,0001 \\
Duncan's MRT & 20,59 \\
\hline
\end{tabular}

Keterangan:

' Jumlah artopoda non-target yang terbunuh = jumlah artopoda non-target yang mati dan tertangkap pada kain hampar berukuran $1 \mathrm{~m} \times 1 \mathrm{~m}$.

${ }^{2}$ Nilai tengah pada satu lajur yang diikuti oleh huruf yang sama, artinya tidak berbeda nyata berdasarkan uji Duncan's MRT ( $\alpha=0,05)$.

${ }^{-}$Pengaruh perlakuan berbeda sangat nyata. 
Hal ini memberi indikasi bahwa penyemprotan permetrin pada tanaman kakao mempunyai dampak buruk terhadap berbagai jenis artropoda non-target yang dapat bermanfaat secara langsung maupun tidak langsung dalam menjaga kestabilan agroekosistem tanaman kakao.

\section{SIMPULAN}

Hasil percobaan di lapangan menunjukkan bahwa aplikasi insektisida permetrin pada tanaman kakao membunuh hama pengisap buah (Helope/tis spp.) secara nyata apabila dibandingkan dengan kontrol. Selanjutnya hasil percobaan di akhir pengamatan (72 jsa) menunjukkan bahwa aplikasi insektisida permetrin pada konsentrasi 200 dan 250 ppm membunuh semua serangga uji (Helopeltis spp.). Namun selain efektif membunuh serangga hama, insektisida permetrin juga berdampak buruk pada artropoda non-target. Sebanyak 22 famili kelompok artropoda yang ditemukan terbunuh akibat perlakuan insektisida permetrin. Selain itu jumlah artropoda yang terbunuh akibat perlakuan insektisida permetrin $(27,3 ; 47,0 ;$ dan 85,3 ekor/kain hampar pada konsentrasi 100 ; 200 ; dan 250 ppm) nyata lebih tinggi dibandingkan dengan kontrol $(4,3$ ekor/kain hampar) kecuali konsentrasi terendah $(50 \mathrm{ppm}=16,7$ ekorkain hampar).

\section{SANWACANA}

Penulis mengucapkan terimakasih kepada Staf dan Karyawan perkebunan kakao PT Pluit Makmur Lestari, Cabang Lampung di Desa Bernung, Kecamatan Gedongtataan Lampung Selatan, yang telah memberikan izin dan bantuan teknis dalam pelaksanaan penelitian ini. Ucapan terima kasih juga disampaikan kepada Saudara Nurafiah Karmike atas bantuan pelaksanaan penelitian ini dan PT Probio atas dukungan dana.

\section{DAFTAR PUSTAKA}

Alias, A., M. Rita. \& K.C. Khoo. 1988, Comparative merits of cocos pod and shoot as food sources of the mirid Helopeltis theobromae. The Planter. Kuala Lumpur 64:100-104.
Bigger, M. 1993. Ant Homopteran interactions in a tropical ecosystem - description of an experiment on cocoa in Ghana. Bull.Entomol. Res. 83(4): 475-505.

Chung, G.F. \& B.J. Wood. 1989. Chemical control of Helopeltis theobromae Mill. And crop loss assessment in cocoa. J. Plant Prot. Trop. Kuala Lumpur: The Malaysian Plant Prot. Soc. 6(1): 35-48.

Kalshoven, L.G.E. 1981. The Pests of Crops in Indonesia. Revised and translated by P.A. Van der Laan. PT Ichtiar Baru - Van Hoeve. Jakarta.

Khoo, K.C. \& R. Mohamad. 1986. Ecology of cocoa (Theobroma cacao) mirids (Peninsular Malaysia). $2^{\text {nd }}$ International Conference on Plant Protection in the Tropics $3 ; 38-40$,

Muhamad, R \& M.J. Way. 1995, Damage and crop loss relationships of Helope/tis theivora, Hemiptera: Miridae and cocoa in Malaysia. Crop Protection 14: 117-121.

Smith, E.S.C. 1978. Host plant and distribution records Helopelis claciver (Walker) (Heteroptera: Miridae) pest of Theobroma cacao and Camelia sinensis in Papua Guinea. Papia New Guinea Agric. J. Port Moesby. Dept. of Agric, Stock qand Fisheries. $29(1 / 4)$ : 14.

SAS Institute Inc, 1988. SAS/STATA User's Guide. Release 6.03 Edition. Cary, NC.

Siregar, T., Riyadi, \& Nuraeni. 1999. Budidaya, Pengelohan dan Pemasaran Coklat. Penebar Swadaya. Jakarta.

Sudarmadji, D., S. Sosromasono, S. Wardoyo, \& H. Suseno. 1990, Development of Helopeltis antonii on pod of fine flavour cocoa and bulk cocoa. Menara Perkebunan 58(3): 84-87. 